\title{
Li vida de Doucelina de Dinha, de Felipa Porcelleta. Imaginería, prácticas devocionales y legitimación de la vida beguina en el Mediterráneo
}

Felipa Porcelleta es, actualmente, una de las escritoras que menor atención ha recibido dentro del contexto de la espiritualidad medieval. La hagiografía que ésta escribió sobre su compañera Doucelina de Dinha ha pasado casi desapercibida dentro del marco académico, todo ello a pesar de proporcionar una información de gran valor para comprender un fenómeno tan heterogéneo y complejo como la espiritualidad beguina. Así, el propósito de este artículo será, en primer lugar, conocer las prácticas devocionales y el recorrido vital de Doucelina de Dinha a partir, mayormente, de la obra de Felipa. A continuación, se intentará focalizar el análisis en los propósitos literarios de la segunda, que encauzó claramente su relato en la imaginería de la mística floreciente de ese siglo XIII y concibió la escritura de la Vida como plataforma de legitimación del modo de vivir que defendían las así llamadas “donnas de Roubaut”. Estas consideraciones, sin embargo, serán expuestas de manera sintética, por lo que la pretensión última de tales análisis será reubicar dicha obra dentro del mapa europeo de espiritualidad medieval, un primer paso para el desarrollo de eventuales trabajos posteriores de mayor profundidad.

\section{Felipa Porcelleta (1250-1316)}

Si bien toda la información de la que disponemos sobre Doucelina (1214-1274) se ciñe a la Vida escrita por Felipa y a las sucintas notas de la crónica del franciscano

\footnotetext{
Nota: Este trabajo ha sido realizado en el marco del laboratorio de excelencia LabexMed - Les sciences humaines et sociales au coeur de l'interdisciplinarité pour la Méditerranée, referencia 10-LABX-0090. Asimismo, este trabajo se ha beneficiado de una ayuda del estado francés gestionada por la Agence Nationale de la recherche, dentro del proyecto Investissements d'Avenir $A^{\star}$ MIDEX, referencia $n^{\circ}$ ANR-11-IDEX-0001-02.
}

Sergi Sancho Fibla, Aix-Marseille Université / CNRS, TELEMMe

๖ Open Access. (C) 2018 Sergi Sancho Fibla, published by De Gruyter. (๕) BY-NC-ND This work is licensed under the Creative Commons Attribution-NonCommercial-NoDerivatives 4.0 License. https://doi.org/10.1515/9783110596755-023 
Salimbene de Adam (1221-1290), ${ }^{1}$ en el caso de la autora la situación es bien distinta. De Felipa se han conservado numerosos documentos notariales que nos ayudan a reconstruir la vida, familia y negocios de una mujer perteneciente a uno de los linajes más poderosos de la región. ${ }^{2}$ En ellos se refleja la relevancia de esta beguina en el panorama social de la época. Martin Aurell apunta que podría haber nacido en 1250, hija de Guilhem Porcelleta (1217-1288), señor de Arles. ${ }^{3}$ Felipa se casó muy joven con Fouques de Pontevès, señor de Artignosc, que residía en Barjols. Allí es donde probablemente encontró a Doucelina, natural de la misma ciudad. De ese matrimonio Felipa tuvo dos hijas: la primera llamada Mabila y la segunda, precisamente, también Doucelina. A la edad de veintiún años se encontró viuda y sin la custodia de sus hijas, arrebatadas por Margarita de Pontevès, su suegra. Con ésta, de hecho, mantendría reiterados pleitos y conflictos legales a propósito de la custodia de sus descendientes y de la herencia de su difunto marido. ${ }^{4}$ En 1274 Felipa decidió entrar en el beguinaje de Marsella, fundado por su amiga Doucelina. Más tarde, llegaría a ser priora (XIV, 23) $)^{5}$ un pilar esencial del sustento económico de la comunidad. ${ }^{6}$ En efecto, es ella la que, en 1294, compra al vizconde de Marsella una gran parte de las propiedades de la calle donde se encontraba el edificio que acogía a las religiosas para así construir un bloque de dimensiones apropiadas a una comunidad en auge considerable. ${ }^{7}$ Felipa hizo testamento en 1312 y murió en 1316. En dicho documento podemos entrever la voluntad de asegurar la supervivencia del beguinaje: declara como herederas universales a sus nietas, beguinas en Marsella, a condición de que se

1 Fratis Salimbene de Adam, Cronica, ed. de O. Holder Egger, Bari, G. Scalia (MGH Scriptores, XXXIII), 1966.

2 Documentos recogidos en M. Aurell, Une famille de la noblesse provençale au Moyen Âge: Les Porcelet, Avignon, Aubanel, 1986.

3 M. Aurell, cit., p. 166.

4 El testamento de Felipa fue recopilado y publicado por Albanès en la edición de La Vida. F. Porcelet, La Vie de Sainte Doucelina, fondatrice des Beguines de Marseille, Éd. et trad. par J.H. Albanès, Marseille, Camoin, 1879, pp. 270-275. Al final de este volumen se añadieron las "Pièces justificatives" en las que aparecen, además de otros documentos que conciernen a Felipa (pp. 262-263), testamentos de otras beguinas, censos, un himno y una fórmula de profesión que usaban las mismas, contratos y compras de las religiosas o incluso las bulas de Juan XXII a propósito de esta comunidad.

5 Cuando se haga referencia a La Vida editada por Albanès (F. Porcelet, cit.), se citará, dentro del texto, el pasaje exacto con el número de capítulo y el párrafo entre paréntesis. Esta decisión pretende ayudar a los lectores que dispongan de otras ediciones posteriores a la de Albanès. $\mathrm{Si}$ las citas a La Vida son múltiples, se muestran como nota al pie para así no entorpecer la lectura. 6 Cfr. K. Garay - M. Jeay, “Introduction”, in The Life of Saint Doucelina, Beguine of Provence. Translated by Kathleen Garay et Madeleine Jeay, Cambridge, D.S. Brewer, 2001, p. 16.

7 Cfr. M. Aurell, cit., p. 168 y F. Porcelet, cit. p. XXXII. 
quedaran en él (una preocupación constante que, como veremos al final de este artículo, aparece de manera manifiesta en La Vida). ${ }^{8}$

\section{La vida de Doucelina}

En lo que concierne a la obra, cabe decir que ha sido comúnmente aceptada la autoría de Felipa, aunque el texto no aparece firmado más que por su copista. Del manuscrito existieron dos versiones diferentes. La primera, fechada en 1297, ha desaparecido, así que únicamente se conserva la de 1315, escrita en occitano. ${ }^{9}$ Este manuscrito aparece, además, seguido de una profesión de fe y un himno a las beguinas que las mismas ediciones reproducen.

La estructura de esta obra merecería un estudio de mayor extensión, pero sucintamente se puede apuntar que se trata de una organización de contenidos simétrica que responde a los cánones de las hagiografías de santos mendicantes y terciarios de su época. ${ }^{10}$ La obra vertebra el relato a partir del recorrido vital, pero lo divide en dos grandes bloques: los primeros ocho capítulos conciernen a la naturaleza virtuosa pero terrenal de Doucelina, mientras que los siete del segundo aluden a sus cualidades y vivencias trascendentales. Por último, con el fin de mantener la simetría, un último capítulo aparece como colofón, en el que se alaba y bendice a la santa, a las beguinas y a las ciudades de la región. Dentro del primer grupo se puede además discernir entre los tres primeros capítulos, referentes a la formación de la santa y de sus dos beguinajes, y los otros cinco, que desarrollan las virtudes que hacían de ella un ejemplo para su comunidad. En el segundo bloque también encontramos tal división, entre los cuatro primeros capítulos, dedicados a experiencias transcendentales que realizó en vida (éxtasis, visiones, profecías y milagros) y los tres siguientes, que conciernen a las experiencias sobrehumanas acaecidas durante y después de su muerte (cfr. Tabla 1).

Doucelina, por su parte, nacida en 1214, era hija de comerciantes, tuvo dos hermanos, uno de ellos murió joven y el otro llegó a ser una de las referencias internacionales del franciscanismo: Hugo de Digne (ca. 1205-1256). ${ }^{11}$ La hagiografía que escribe Felipa sigue a grandes rasgos las Vidas típicas de la época,

8 F. Porcelet, "Pièces justificatives”, cit., p. 274.

9 El manuscrito se encuentra actualmente en la BnF de París, bajo el código Fond fr. 13503.

10 Cfr. D. de Courcelles, Quelques histoires belles et véritables des femmes au Moyen âge et à la Renaissance, in "Summa”, 5 (Primavera 2015), pp. 88-106 (p. 91).

11 Cfr. D. Ruiz, Frère Hugues de Digne et son oeuvre (édition critique). Une histoire par les sources narratives, la codicologie et la doctrine (XIII ${ }^{e}-X V^{e}$ siècles), Thèse de doctorat, sous la dir. de André Vauchez - Antonio Rigon, Paris X Nanterre - Università degli Studi di Padova, 2009. 
Tabla 1: Estructura de Li vida de Doucelina de Dinha.

\begin{tabular}{|c|c|c|c|}
\hline \multirow{16}{*}{ Recorrido vital } & \multirow{8}{*}{$\begin{array}{l}\text { Vivencias y } \\
\text { experiencias de su } \\
\text { vida terrenal }\end{array}$} & \multirow{3}{*}{$\begin{array}{l}\text { Infancia y fundaciones } \\
\text { de los beguinajes }\end{array}$} & 1. Infancia \\
\hline & & & $\begin{array}{l}\text { 2. Formación y } \\
\text { conversión }\end{array}$ \\
\hline & & & $\begin{array}{l}\text { 3. Fundaciones de } \\
\text { leras y Marsella }\end{array}$ \\
\hline & & & 4. Humildad \\
\hline & & & 5. Pobreza \\
\hline & & Ejemplo virtuoso & $\begin{array}{l}\text { 6. Ejemplo y dirección } \\
\text { espiritual en las } \\
\text { comunidades }\end{array}$ \\
\hline & & & 7. Compasión \\
\hline & & & 8. Caridad \\
\hline & \multirow{8}{*}{$\begin{array}{l}\text { Experiencias } \\
\text { sobrehumanas }\end{array}$} & \multirow{4}{*}{$\begin{array}{l}\text { Experiencias } \\
\text { trascendentales } \\
\text { en vida }\end{array}$} & $\begin{array}{l}\text { 9. Éxtasis y } \\
\text { levitaciones }\end{array}$ \\
\hline & & & $\begin{array}{l}\text { 10. Oración y } \\
\text { contemplación (visiones) }\end{array}$ \\
\hline & & & 11. Profecías \\
\hline & & & 12. Milagros \\
\hline & & \multirow{4}{*}{$\begin{array}{l}\text { Experiencias } \\
\text { trascendentales } \\
\text { post-mortem }\end{array}$} & 13. Muerte \\
\hline & & & $\begin{array}{l}\text { 14. Entierro y } \\
\text { traslación del cuerpo }\end{array}$ \\
\hline & & & $\begin{array}{l}\text { 15. Milagros } \\
\text { post-mortem }\end{array}$ \\
\hline & & & 16. Bendiciones \\
\hline
\end{tabular}

describiendo su disposición a la oración desde pequeña, así como una curiosa tendencia a la soledad y a las horas nocturnas. ${ }^{12}$ Este comportamiento se radicalizó con la muerte de su madre, pues partió con su padre a vivir a Ieras (Hyères) y allí se dedicaron los tres al cuidado de enfermos y leprosos (I, 5-7). Después de la muerte de su progenitor y al ausentarse su hermano a París durante dos años, Doucelina entró en un convento de clarisas de Gémenos (II, 7). Sin embargo, poco después regresó a Ieras, decidida a fundar una comunidad de beguinas. Sería lícito preguntarse cómo se impone una decisión de tal género a una joven provenzal cuando no existían beguinas en el sureste francés (y ello lo deja manifiesto

12 Respecto a su propensión a la soledad: I, 3-4; VIII, 45-47; IX, 4-8; IX, 26-28. En cuanto a su inclinación para la oración nocturna, entre otros: VI, 13; IX, 28; IX, 46. 
la Vida: "en aquel temps, non era estament de beguinas, ni en Proensa non las auzian mentaure", II, 2). ${ }^{13}$

Así, Doucelina fundó entre 1240 y 1242 la primera comunidad, llamada "de Roubaut” por la cercanía al río que lleva el mismo nombre. La casa se ubicó anexa a la muralla de la ciudad, es decir, alejada del centro urbano, apuntando ya desde su fundamento a un ideal de vida semi-monástica. Su hermano la ayudó activamente en esta tarea, realizando un sermón ante una asistencia extraordinariamente numerosa después del cual atestiguó el voto de celibato y de virginidad de su hermana ante Dios. La Vida asegura que fue tan convincente el espectáculo que ciento treinta mujeres hicieron voto de virginidad y más de ochenta de castidad (II, 10).

Después de la formación de esta primera comunidad en Ieras, Doucelina fue hasta Marsella para fundar una nueva, vinculada a la primera y con el mismo nombre, pero un clima político embrollado complicó la tarea. ${ }^{14}$ En 1257 consiguió su cometido y desde entonces administró ambas casas. Por lo que se desprende de la vida, no fue sólo fundadora, sino también priora activa en la educación

13 Los editores y críticos de la obra han apuntado siempre hacia su hermano como promotor de este tipo de vida como beguina. Así, Albanès indica que, al pasar su hermano dos años en París, tuvo la oportunidad de conocer los beguinajes del Norte y se lo trasmitió a su hermana. F. Porcelet, cit., p. XLIII. Tal idea ha sido reproducida en A. Sisto, Figure del primo francescanesimo in Provenza. Ugo e Douceline de Digne. Firenze, Olschki, 1971, pp. 34-35. Por otra parte, Attard alude a la posibilidad de que su padre, mercader, tuviera conocimiento de las comunidades beguinas de Flandes y Alemania. Cfr. J.-P. Attard, Religion, sainteté et pouvoir en Provence angevine, première maison d'Anjou, modèle et miroir du monde angevin (1246-1382), Thèse de doctorat, sous la dir. de Jean-Paul Boyer, Aix-Marseille Université, 2015, p. 135. Véase también E. W. McDonnel, Beguins and Beghards in Medieval Culture, with Special Emphasis on the Belgian Scene, New Brunswick, New Jersey, Rutgers University Press, 1954, p. 82. Lo cierto es que la Vida manifiesta el poder agente de Hugo en el establecimiento del primer beguinaje de Doucelina, invocándolo como "maestro de nuestra orden" ("nostre sant paire fraire Hugo que aquest estament a enseinnhat”, X, 36). No obstante, situarlo como fuente de la voluntad de Doucelina resulta un tanto arriesgado. De hecho, la misma hagiografía explicita que la intención primigenia es de Doucelina, quien pidió consejo a su hermano para que le diera una "forma y manera de vivir a Dios": "La quai cauza plus fizelmens a far e plus veraia, vole illi aver per lo dechat el conseill dell sant paire [...] requerent li humillmens e devota, qu'el dones lur forma e maniera de vieure a Dieu" (III, 4).

14 El clima al cual se alude se refiere a las luchas, acaecidas entre 1250 y 1257, entre el municipio y Carlos de Anjou, conde de Provenza. El primero quería mantener sus privilegios, mientras el segundo pretendía derogarlos. Los Franciscanos, tan cercanos a Doucelina y a sus comunidades, habían apoyado al municipio, así que la relaciones entre el poder angevino y los frailes se volvieron más que tensas. Cfr. J.-P. Attard, cit. p.137. La hagiografía declara a tal respecto que fueron precisamente Doucelina y Hugo quienes jugaron un rol crucial para que los frailes menores reencontraran la consideración del conde (IV, 10-14). 
corrección, aleccionamiento y vigilancia de las jóvenes beguinas (v.g. III, 7; VI, 11). Cuando murió, en 1274, floreció una devoción popular desmesurada que provocó altercados, peregrinaciones y el nacimiento de un culto a sus reliquias como bienes de curación (caps. XIII-XIV).

\section{3 Éxtasis y visiones}

De la imaginería que emplea Felipa para describir las experiencias de Doucelina podría destacarse, en primer lugar, la referente a la Pasión. Las visiones del Cristo crucificado son habituales durante sus experiencias extáticas. Un ejemplo de ello es la imagen de la exposición de las llagas, una escena que presenta unas semejanzas evidentes con el motivo iconográfico del "Entierro de Jesucristo mostrando las llagas” (X, 13-15). ${ }^{15}$ De hecho, el culto a las heridas aparece en varias ocasiones, siempre asociado a la imagen de la abundancia de la gracia, típica de los textos de espiritualidad de la época. En uno de estos casos, se encuentra vinculada a la metáfora de la ebriedad divina, articulada a partir de las imágenes del tonel y el vino (IX, 56). ${ }^{16}$ Sin embargo, las referencias más sorprendentes de la Vida serían las alegorías bélicas utilizando a san Francisco como caballero y sus estigmas como estandarte del ejército de Dios (IX, 42-44; 65-66), así como una descripción geográfica del Paraíso, revelada durante otra visión (X, 12).

15 El motivo de origen bizantino del "Entierro de Cristo mostrando las llagas" pone en escena el cuerpo difunto levantado del sepulcro y exponiendo las llagas como foco de veneración. En un principio, hacia el siglo VIII, los artistas orientales se fijaron al pie de la letra en los Evangelios y, reparando en una representación narrativa explícita, desarrollaron la escena del entierro descomponiéndola en cuadros sucesivos: descenso de la cruz, traslado del cuerpo, vendaje del cadáver y deposición en el sepulcro. Las primeras representaciones en Occidente se encuentran en el norte de la península itálica, donde se puede evidenciar el proceso de emancipación del modelo bizantino. Un modelo que había servido para la meditación a partir de la llegada de los iconos en Occidente, pues el cuerpo inerte de la Pasión permitía mostrar las llagas de modo directo para su contemplación. Cfr. M. Martin, La statuaire de la Mise au Tombeau du Christ des $X V^{e}$ et XVI siècles en Europe occidentale, Paris, Picard, 1997.

16 Se trata de una metáfora que podemos encontrar en numerosos textos de mística cristiana. La ebriedad espiritual, que encontramos en el Cantar de los Cantares $(5,1)$ junto a la imagen de la bodega del esposo $(2,4)$ fueron utilizadas en el contexto espiritual para representar el lugar de encuentro de la unión mística, así como el arrobamiento desmesurado de tal fenómeno. Véanse, por ejemplo, las Cartas 273 y 373 de Catalina de Siena o, para un análisis de las imágenes en el caso de Marguerite Porete, P. García Acosta, Poética de la visibilidad del Mirouer des ames simples de Marguerite Porete, Tesis doctoral dirigida por Victoria Cirlot, Universitat Pompeu Fabra, 2009, pp. 16-17, pp. 160-161. 
Cabe destacarse asimismo el lugar que ocupan la eucaristía y la imaginería angélica en muchas de sus experiencias. En el primer caso encontramos fenómenos similares a los ya estudiados alrededor de la hostia, como éxtasis, ${ }^{17}$ levitaciones, ${ }^{18}$ ayunos, ${ }^{19}$ la atracción de su cuerpo hacia el tabernáculo $(\mathrm{X}, 13)$ o desmayos después de ingerirla. ${ }^{20}$

Por lo que concierne a la imaginería angélica, podemos destacar la visión de una escalera dorada que comunicaba la tierra con el cielo y la Trinidad (X, 21-25). Si bien la entidad trinitaria no se encuentra descrita de forma precisa, sí se explica cómo los ángeles subían y bajaban por ella, a modo de las representaciones de la escalera de Jacob que encontramos en el arte de la época. ${ }^{21}$ Pero la presencia de ángeles fue una constante en la vida de Doucelina, hasta el punto que la misma fue convirtiéndose poco a poco en dicho ser a los ojos de los demás (XIII, 8). ${ }^{22}$ El proceso se aceleraba y culminaba a medida que se aproximaba su muerte. Al final de su vida, Doucelina estaba tan cerca de los ángeles que podía incluso responder las dudas que las otras beguinas le planteaban sobre ellos, por ejemplo, a propósito de la comunicación entre Dios y los seres celestiales, careciendo el primero de boca y lengua (IX, 68).

17 IX, 45-47; IX, 67; IX, 69; XIII, 5.

18 Tales levitaciones debieron ser controvertidas, pues en todo caso se intenta garantizar su veracidad con testimonios que, o habían colocado su cabeza entre los pies de Doucelina y el suelo, o bien habían medido cuidadosamente la distancia (siendo ésta en todo caso de un palmo): IX, 6; IX, 8; IX, 9; IX,12; IX, 58; IX, 69.

19 VII, 4; IX, 46; IX, 52-53; IX, 55.

20 Las experiencias extáticas alrededor de la eucaristía son habituales sobre todo en los textos de la mística femenina. Mayormente fue a partir de la introducción de forma regular de la elevación de la hostia en la misa, a inicios del siglo XIII, cuando florecieron todo tipo de visiones relacionadas con la exhibición del cuerpo, las heridas y la sangre de Cristo. Cfr. C. W. Bynum; Holy Feast and Holy Fast: The Religious Significance of Food to Medieval Women, Berkeley and Los Angeles, University of California Press, 1987 y de la misma autora: The Body of Christ in the Later Middle Ages: A Reply to Leo Steinberg, in "Renaissance Quarterly”, 39 / 3 (Autumn, 1986), pp. 399-439.

21 Este motivo está presente en el Génesis (28), concretamente en el pasaje de la visión de Bethel, en la que Jacob ve a los ángeles ascender y descender por una escalera que comunica el cielo y la Tierra. Las ilustraciones de dicha escalera aparecen en los siglos X y XI y articulan el ascenso y el descenso en clave moral, un matiz que no se encuentra en la visión de Doucelina. Para el motivo iconográfico, cfr. J. R. Martin, The Illustration of the Heavenly Ladder of John Climacus, Princeton, Princeton University Press, 1954.

22 Se describen visitas de ángeles (X, 5), se realizan comparaciones entre las beguinas y los seres celestiales (III, 9) y en particular entre Doucelina y estos mismos (IX, 74; IX, 3; IX, 24). Aparecen además ciertas confusiones entre la santa y los ángeles en escenas ritualizadas, ya sea por una procesión (IX, 59-64) o por el canto (IX, 9; IX, 70; XIV, 11; XIV, 24-26). 


\section{Prácticas}

Respecto a las prácticas de devoción que atestigua la Vida, podemos mencionar, en primer lugar, la oración nocturna, reiterada una y otra vez con énfasis en el relato (v. g. IX, 46). Esta es, de hecho, una de las manifestaciones de esa disposición a la soledad que ya se apuntaba en la infancia y que incluso más tarde, se perpetúa en la presencia de un oratorio secreto que le permitía entregarse a la devoción en completo aislamiento.

En segundo lugar, la Vida alude en repetidas ocasiones a la mortificación de la carne a la que se somete la santa, mediante un cilicio y otros variados instrumentos (I, 13). Torturas y suplicios (VI, 4) que ella misma se realizaba, como por ejemplo las heridas en las manos que se infligía cada vez que sentía que iba caer en rapto estando en público (IX, 31-32). ${ }^{23}$ Un comportamiento que recuerda a otro episodio en el que reprende a sus compañeras por haberla dejado mostrar en público su experiencia extática de levitación (IX, 40-41). Además de practicarse heridas superficiales, Doucelina practicaba ayunos continuados y largas sesiones de llanto, concebido éste no como gracia o don, sino como ejercicio automatizado y programado diariamente. ${ }^{24}$ Estas prácticas la sumían en estados extáticos tales como las levitaciones, el sonambulismo, el canto divino ininteligible (IX, 69-70) y los gritos. ${ }^{25}$ Como es habitual en las hagiografías, estos ataques extáticos se disponen en un orden paralelo al calendario litúrgico. ${ }^{26}$ Entre tales fechas, el día de la festividad de la virgen toma un relieve especial durante todo su recorrido vital, aunque especialmente el día de su muerte. En la descripción de su fallecimiento Felipa diviniza a Doucelina, al describir su defunción como si se tratara de la asunción de María (XIII, 6). Esta pseudo-deificatio, sin embargo, puede intuirse en otros puntos de la narración. Por ejemplo, en varias ocasiones se describe cómo la santa levitaba y se elevaba con los brazos en cruz. ${ }^{27}$ La beguina asumía

23 Sin embargo, ella exhortaba a sus compañeras a no realizar prácticas de mortificación del cuerpo (VI, 12).

24 III, 8; VI, 13-15; VI, 7; VII, 3-4. Para un estudio sobre el don de las lágrimas en las obras de espiritualidad medieval, véase P. Nagy, Le don des larmes au Moyen Âge. Un instrument spirituel en quête d'institution ( $V^{\mathrm{e}}$-XIII ${ }^{\mathrm{e}}$ siècles), Paris, Albin Michel, 2000.

25 VII, 7; IX, 55; IX, 57.

26 Por ejemplo, entre otros pasajes, en el capítulo IX encontramos la siguiente sucesión lógica: Navidad (IX, 45-47); Viernes Santo (IX, 48-57), Pascua (IX, 58-64) y Pentecostés (IX, 65-66).

27 Esta imitación de la cruz la podemos ver en IX, 39 y IX, 55, pero no es el único pasaje. En otra ocasión aparece una emulación de la virgen cuando Felipa explica que la condesa soñó que del pecho de Doucelina manaba aceite para iluminar como el que se usaba para las lámparas (X, 11). Más adelante, es la misma beguina la que vio a María dando a luz, mientras de su seno surgía un rayo de Sol en cuyo extremo aparecía Cristo. Por otra parte, cabe también resaltar la 
así el rol redentor de Cristo mediante la imitación de su figura. Uno de los milagros (XII, 26), de hecho, sigue este mismo objetivo, pues se vincula claramente con la escena de las Bodas de Canaán (Juan II, 1-11). Finalmente, antes de morir, se nos relata cómo la santa pasa tres días y tres noches en éxtasis, esquema que tiene sin duda un eco crístico y, en añadidura, en su último suspiro declara: "in manus tuas. Domine, comendo spiritum meum" (XIII, 13), frase que reverbera en una de las septem verba que pronunció Cristo al dejar el mundo (Lucas, 23: 46).

Detrás de una pátina de obligada modestia se esconde una figura altamente instruida y con un fuerte lazo con uno de los franciscanos de influencia espiritual e intelectual más notable de su tiempo. ${ }^{28} \mathrm{Su}$ hermano fue un reformador de influencia joaquimita que pudo haberla iniciado en el conocimiento profundo de la religión y de la administración de la iglesia. ${ }^{29}$ Tanto es así que en la vida se nos cuenta que frailes y clérigos iban a verla para que les aconsejase en cuestiones de fe y teología (IX, 29-30; XI, 1-2). Asimismo, la beguina llegó a altas cotas de celebridad en la corte y fuera de ella. El conde Carlos I y su mujer demostraron devoción hacia ella y hacia su comunidad, y por lo que se relata en la Vida, a partir de un cierto momento se vio obligada a no mostrarse en público. Sobre todo, no debía hacerlo cuando experimentaba sus éxtasis, puesto que el pueblo corría en masa para verla contemplar en ese estado". ${ }^{30}$ La pasión desaforada era tal que las beguinas tenían miedo, pues veían a la muchedumbre escalar los barrotes hasta casi romperlos (IX, 24) y la misma Doucelina tuvo que renunciar a acudir a la capilla de los franciscanos por la alarma social que provocaba su presencia (IX, 26).

Todo ello, junto a los milagros que realizó en la ciudad de Marsella hicieron que a su muerte su cuerpo se convirtiera en un objeto de culto. ${ }^{31}$ A sus 60 años, en

comparación entre Doucelina y Cristo (XIII, 10) basada en un comportamiento tradicionalmente maternal, lo cual no resulta sorprendente en el contexto espiritual del Medioevo. Cfr. C. W. Bynum, Jesus as Mother, Berkeley, University of California Press, 1982.

28 Al topos de modestia nos referimos precisamente cuando Felipa afirma que Doucelina era una religiosa carente de la sutileza de las letras (XI, 1) pues, además del dominio de la lectura y la escritura que se le puede suponer por su entorno social, por la administración de las dos casas y por las diferentes prácticas de la oración, aparecen dos pasajes en la Vida que contradicen la afirmación anterior. En ellos se explicita que la santa leía a menudo la vida de san Francisco (IX, 44) y la de otros santos (VIII, 10).

29 C. Carozzi, Une béguine joachimite. Douceline, soeur d'Hugues de Digne, in “Cahiers de Fanjeaux”, t.10, 1975, pp. 169-201 (p. 200).

30 "Tan grans era le pobols que hi si acampava, per vezer e per esgardar la en aquel estament" (IX, 24).

31 Es interesante ver cómo los milagros realizados por Doucelina están íntimamente asociados al cuerpo, ya sea por enfermedad o por fecundación. Respecto a los milagros realizados en vida, podemos encontrar hasta siete en los que se realiza una cura a una enfermedad, otro en el que 
1274, Doucelina se elevó dejando el cuerpo con sus hijas de Roubaut. Alrededor de éste el pueblo marsellés no tardó en reunirse en masa intentando tantear el cuerpo santo, usurpando cualquier objeto que estuviera en contacto con el mismo (XIII, 16) y llegando a hacer trizas su ropa (XIII, 16). Este impetu hizo temer a los franciscanos que el cuerpo sufriera las mismas consecuencias durante su traslado a la capilla, así que necesitaron que "gente armada" lo transportara desde el convento hasta la iglesia de los frailes menores, no sin tumultos y desórdenes (XIII, 18), pues Felipa declara que hubo que cambiar hasta tres veces el lienzo que la cubría, desgarrado y arrebatado por el gentío (XIII, 20).

La lectura de la vida de Doucelina deja claras dos cuestiones principales. La primera es que, no obstante haber quedado al margen de los estudios comparativos sobre mística femenina medieval, el relato se entronca claramente con la espiritualidad cristiana de su tiempo. Las prácticas, las experiencias y la imaginería que evoca la Vida no dejan lugar a dudas. La segunda, es que, más allá de las fórmulas orientadas a una posible beatificación, se manifiesta una voluntad de legimitación, no solo de las vivencias de la religiosa en cuestión, sino de la existencia de la comunidad de beguinas. Una cuestión que sin duda resulta comprensible conociendo los conflictos que éstas suscitaron a finales del siglo XIII y principios del XIV. ${ }^{32}$

\section{Legitimación y conclusión}

En estas breves líneas se ha podido demostrar la heterogénea espiritualidad de las beguinas de Marsella y Ieras, su evidente vínculo con el franciscanismo ${ }^{33}$ y la

evita una contienda y otro relacionado con el parto de una mujer. Por su parte, en los postmortem encontramos doce asociados a curas de enfermedades y otros dos a la fecundación femenina.

32 Cfr. L. A. Burnham, So Great a Light, So Great a Smoke. The Beguin Heretics of Languedoc, Ithaca, Cornell University Press, 2008 y McDonell, cit.

33 Las relaciones de las beguinas con los frailes menores son particularmente intrincadas. Las "Donnas de Roubaut" seguían las misas en la iglesia de los franciscanos (IX, 45-46), ya sea en Ieras como en Marseille, el confesor de Doucelina fue el obispo de Orange, Josselin (IV, 9), al que le promete voto de obediencia, y quien fue asimismo ministro provincial de los menores en la Provenza. Fue él, de hecho, quien pronunció el panegírico después de la muerte de la priora. Por otra parte, uno de los pocos a los que se nos dice que Doucelina pidió consejo es Giovanni da Parma, fraile cercano a Hugo, como él fiel secuaz de las teorías de Gioacchino da Fiore. Los franciscanos mismos realizaron una procesión durante tres días alrededor del cuerpo santo ya muerto, lo que significa que consideraban y honraban a Doucelina como perteneciente a su familia religiosa. Los restos, de hecho, fueron depuestos en un sepulcro de mármol en la vieja iglesia de los Menores (cap. XIV). En lo referente a Felipa, ella misma tenía en su familia 
conjunción de la imaginería de Doucelina y Felipa con la mística de su tiempo. Sin embargo, como se ha mencionado en la "Introducción", este artículo no es sino un primer paso para un estudio futuro, necesariamente de mayor amplitud. Resultará, en este sentido, indispensable un análisis de las visiones y su relación con la iconografía de la época, así como una investigación que pueda focalizar en las operaciones de legitimación que se articulan en la Vida y que pueden ser corroboradas mediante otros documentos del beguinaje. Esta última es, sin duda, la cuestión más compleja de la hagiografía, un aspecto que debería leerse bajo el prisma de los conflictos que el movimiento beguino suscitó en Flandes o en las tierras del Rin. En efecto, desde 1274 encontramos ya en el concilio de Lyon el primer aviso y en 1311 la condena a las beguinas, a partir del concilio de Vienne que se celebró bajo el papado de Clemente V. La segunda versión del texto de la Vida data de 1315, por lo que sería posible que se tratara de una modificación prudente del texto inicial de 1297. Una corrección que probablemente quisiera, no sólo mitigar la heterodoxia de su fundadora, sino también intentar justificar la existencia de estas comunidades en Provenza.

En efecto, Felipa pone en juego toda una serie de estrategias para legitimar la vida de su comunidad, pues, en primer lugar, se manifiesta en su escrito una autoconsciencia del carácter único y heterodoxo de las "donnas de Roubaut”: se explicita que fueron la primera comunidad de este tipo en Provenza $^{34} \mathrm{y}$ se señalan los peligros y las amenazas que sufrieron por parte de "gente que se esforzó en deshacer lo que Doucelina hizo" (X, 16). En segundo lugar, resulta evidente la voluntad de Felipa de afirmar la identidad de su comunidad a partir de sus signos de reconocimiento como son el velo (II, 4) y, especialmente, el color de sus vestimentas (II, 8-9; XIV, 13-15).

Sin embargo, no era la intención de Felipa separarse de la vivencia común de la espiritualidad cristiana, pues se manifiesta en varios pasajes el interés en asemejar los beguinajes a una orden establecida. Por una parte Doucelina pide a

\footnotetext{
miembros que formaban parte de comunidades franciscanas. Ella misma también decidió ser enterrada en el cementerio de la orden de S. Francisco. Y, por último, cuando ella decide poner por escrito la santa vida de la que había sido su priora, las obras que le servirán de modelo serán, precisamente, las vidas del poverello de Tomaso da Celano y de Buenaventura. En este sentido se pueden entrever semejanzas estructurales y temáticas con la hagiografía de Buenaventura: el origen mercader de la santa, el servicio a pobres y enfermos, el don de las lágrimas, los estigmas (IX, 31-32), el trato al cuerpo milagroso y el amor a los animales (X, 26-29; VII, 1-2; VIII, 2; IX, 19; X, 26-29). Por último, cabe decir que cuando murió Margarite d'Alon, la última priora de Roubaut, dejó el beguinaje y todas las propiedades heredadas durante casi dos siglos a los frailes menores de Marsella.

34 "El sancta maire fon en Provensa li premiera beguina, e fon comensamens de totas cellas que preron aquel nom" (II, 11). And: “en aquel temps, non era estament de beguinas, ni en Proensa non las auzian mentaure” (II, 2).
} 
Hugo que escriba una regla (III, 4) y la autora identifica su comunidad como "estament" en varias ocasiones (X, 25; XIV, 33). ${ }^{35}$ Por otra, parece que las "donnas de Roubaut" realizaban votos de castidad (II, 10), de obediencia (VI, 1), de pobreza $(\mathrm{V}, 11)$ y hasta se ha conservado la profesión de fe de las mismas. ${ }^{36}$ El episodio que mejor ilustra este insistente parangón lo encontramos también en la Vida. Allí se nos cuenta que otra beguina de Ieras, estando dormida, le pareció ascender como alma al Paraíso. Entonces vio a una compañera que había muerto recientemente, rodeada de santos y siendo interrogada por éstos sobre era el hábito que llevaba y la orden a la que pertenecía. Ella respondió que había vivido bajo el manto de San Francisco. Al no identificarla como clarisa, los santos quedan dubitativos. Aparece entonces Cristo y éstos se dirigen a él diciendo "Senher, aissi a un'arma, la quall non connoissem, ni sabem de qual estament sia, ni connoiseem son abiti. E dis que sotz la man de sant Frances s'es regida e non porta son abiti, ni de sancta Clara, ni dels autres relegios; ni monega non es, ni non sabem qui sia" (XIV, 28-32). Éste responderá: “son del orden que yo amo y viven bajo la dirección de San Francisco". ${ }^{37}$

En un eventual estudio de esta función legitimizadora de la obra de Felipa también deberá considerarse la relación de las beguinas con el poder. Cabe decir que la "donnas de Roubaut" fueron protegidas por bulas papales de Juan XXII fechadas en 1320, 1323 y $1325 .^{38}$ El pontífice utilizó la así llamada "cláusula de escape" del decreto "cum de quibusdam". ${ }^{39}$ Éste consideraba que las "mujeres fieles” podían continuar con una vida religiosa informal, así que Juan XXII enfatizó en estos tres documentos la vida honesta de la comunidad ("honeste vivunt”), separándolas explícitamente de otras. Asimismo las bulas evocan figuras notables de la Provenza que sin duda ayudaron a tal protección: en la primera se menciona a la Reina de Sicilia, Eleonor de Anjou (nieta de Carlos I).

35 "Sebbene Douceline e le sue compagne non fossero considerate monache, secondo l'opinione comune ["ni monega non es ni non sabem qui sia”!] lo erano secondo la definizione da lui [Hugo, su hermano] data poco oltre "omnes autem mulieres communiter viventes et regularem observantiam canonice profitentes, monache dici possunt” (Expositio Hugonis Super Regulam Fratrum Minorum, de la miscelanea franciscana "Monumenta Ordinis" publicada en Salamanca en 1506, f. 73 b). A. Sisto, cit. p. 138.

36 F. Porcelet, "Pièces justificatives", cit., p. 257.

37 Una frase que, por un lado, aparece en el principio de la Vida, pues es la frase con la que se presentan las dos beguinas que se le aparecen a Doucelina cuando ésta aún es joven. Por otro lado, es evidente que este relato podría aludir a la prohibición, a partir del Concilio Lateranense IV de crear nuevos órdenes.

38 F. Porcelet, "Pieces justificatives”, cit., pp. 275-279.

39 E. Makowski, A Pernicious Sort of Woman: Quasi-Religious Women and Canon Lawyers in the Later Middle Ages, Washington, D.C., Catholic University of America Press, 2005, p. 25. 
En la segunda se evoca al obispo de Marsella, mientras que en la tercera incluso llega a citar nombres de beguinas de Roubaut. Así pues, con ese apoyo el beguinaje pudo continuar existiendo hasta 1407. Cabe añadir, en cuanto a lo que se refiere a los vínculos con el poder que, por un lado, Douceline, después a ayudar a la condesa a dar a luz (IV, 10-14), fue nombrada consejera del conde Carlos I por sus cualidades visionarias y adivinatorias (XI, 3-9). Por el otro, también Felipa podría haber jugado sus cartas, pues la familia Porcellet había entrado en la corte a partir de la rendición de Arles y algunos miembros continuaron sirviendo, por lo menos, a tres generaciones de condes.

Todos estos aspectos pendientes de desarrollo, así como los ya analizados en este artículo deberían servir para colocar a Felipa en el marco del estudio de la literatura espiritual medieval y a Doucelina en el de la mística femenina. El interés que pueden suscitar la estructura de la obra, las visiones de la santa, las prácticas devocionales que se extraen de sus vivencias y las estrategias de legitimación de una comunidad apenas mencionadas poseen un incuestionable valor que raramente ha rebasado el estudio local. Esperemos que este artículo sirva como punta de lanza en la que puedan apoyarse, cual pértiga, futuras investigaciones. 